\title{
Alteração física e morfológica em solos cultivados com citros e cana-de-açúcar, sob sistema tradicional de manejo ${ }^{1}$
}

\author{
Physical and morphological alterations in cultivated soil with citrus and sugar \\ cane, under traditional managing system
}

\author{
Jorge Luís Nascimento Soares ${ }^{2}$ Carlos Roberto Espindola ${ }^{3} \quad$ Luiz Lonardoni Foloni $^{3}$
}

\section{RESUMO}

\begin{abstract}
O uso agrícola contínuo do solo interfere em suas características intrínsecas, em intensidade que varia de acordo com o uso e o manejo praticados. Este trabalho avaliou um Latossolo Vermelho em Bariri(SP), cultivado com citros (Citrus sinensis) e cana-de-açúcar (Saccharum officinarum), sob sistema tradicional de manejo, onde foram estudadas alterações pedológicas decorrentes de um longo período de exploração agrícola. Foram caracterizados: granulometria, porosidade, densidade, matéria orgânica, taxa de infiltração de água e micromorfologia, com alguns parâmetros avaliados estatisticamente por meio de comparação de médias. Em ambos os sistemas de cultivo, a estrutura do solo foi degradada com reflexo negativo no desenvolvimento radicular. Nos solos cultivados com cana-de-açúcar, os tratos culturais mais intensos promoveram maiores alterações, que chegam a atingir camadas mais profundas, com modificações na geometria dos macroporos e surgimento de poros planares e fissurados. Na cultura do citros, o sistema radicular mais profundo e a menor mobilização do solo concorrem para maior estabilidade dos agregados, tornando o ambiente comparativamente mais adequado ao desenvolvimento radicular do que na cana-de-açúcar.
\end{abstract}

Palavras-chave: micromorfologia do solo, estrutura microagregada, taxa de infiltração da água, geometria dos poros.

\section{ABSTRACT}

The continuos use of the soil interferes in its intrinsic characteristics, which changes according to the use and management applied. This present study evaluates some pedologic alterations, resulting from traditional soil management system, in citrus (Citrus sinensis) and sugar cane (Saccharum officinarum) fields subjected to extended planting cycles for a long period. Field and laboratory observations were undertaken in vertical profiles of the Red Latosol in Bariri County, State of São Paulo when morphological descriptions and laboratory analyses (particle size distribution, porosity, bulk density, organic matter, water infiltration rates and micromorphology) were established with some parameters evaluated by means of measure comparisons. The results obtained revealed that the intensive cultivation practices promoted significant soil structure alterations, with difficulty to root growth in both cases. In sugar cane fields, the intensive management promoted great soil structure alterations even in the deeper layers with changing in the voids geometry, which cause planar voids and fissures. In citrus cultivation, the deeper root systems and reduced soil mobility worked together for a greater aggregate stability, promoting adequate root development compared to the sugar cane.

Key words: soil micromorphology, micro-aggregate structure, water infiltration rate, void geometry.

\section{INTRODUÇÃO}

Condições favoráveis de solo, clima e relevo fizeram do município de Bariri, SP, grande produtor agrícola, inicialmente com a lavoura cafeeira e, posteriormente, com os citros e a cana-de-açúcar. No entanto, o uso agrícola intensivo e contínuo desses solos sob práticas convencionais de manejo, especialmente

\footnotetext{
${ }^{1}$ Parte da tese de Doutorado apresentada pelo primeiro autor à Universidade de Campinas (UNICAM), Faculdade de Engenharia Agricola, (FEAGRI), Campinas, SP.

${ }^{2}$ Engenheiro agrônomo, Doutor da Divisão Técnica do Instituto Nacional de Colonização e Reforma Agrária (INCRA), Travessa dos Murucutuns s/nº , 66610-126, Belém, PA. E-mail: jluissoares@ @etscape.net. Autor para correspondência.

${ }^{3}$ Engenheiros Agrônomos, Doutores do Departamento de Água e Solo, UNICAM, FEAGRI, Cidade Universitária Zeferino Vaz, CP 6011, 13081-970, Campinas, SP. E-mail: spin@agr.unicamp.br.
} 
motomecanização, vem reduzindo a sua produtividade, obrigando muitos agricultores a investimentos elevados para a recuperação de suas áreas.

Diversas pesquisas avaliaram os efeitos do cultivo e das práticas de manejo nas propriedades físicas, químicas, e biológicas dos solos (CARPENEDO \& MIELNICZUK, 1990; LUCARELLI, 1997; SILVA \& MIELNICZUK, 1998). Mudanças nessas propriedades são, em grande parte, conseqüência de alterações na estrutura do solo (DREES et al.,1994). O uso agrícola intensivo empregando práticas tradicionais de manejo veio imprimir a necessidade de uma nova abordagem sobre fertilidade do solo (efeito químico), uma vez que os efeitos físicos acabam assumindo uma grande importância, decorrentes dessas práticas de manejo (TAVARES FILHO et al., 1999). A erosão do solo pode ser reflexo, em superfície, de modificações que ocorrem em profundidade, em geral de ordem estrutural (RUELLAN, 1988). Ressalta ainda a necessidade de se atentar ao fato de que a conservação do solo depende mais de atributos morfológico e biológico, do que de atributos químicos.

O objetivo da presente pesquisa foi avaliar as condições físicas e morfológicas de perfis de solos submetidos a sistema de manejo tradicional intensivo, com culturas de citros e cana-de-açúcar cultivadas em uma meia-encosta no município de Bariri, SP, que fundamentem iniciativas para a implantação de modelos alternativos menos impactantes na região.

\section{MATERIAL E MÉTODOS}

Localização e meio físico

O trabalho foi desenvolvido na Fazenda Bananal, município de Bariri,SP, região central do Estado, que faz parte da Província Geomorfológica do Planalto Ocidental, nas proximidades do ponto geográfico de coordenadas 22\%04'00"S e 4842’00"WGr. A área foi desmatada em 1927, para a introdução da cultura do café, que se manteve durante cinco décadas, tendo sido substituída por citros e canade-açúcar, sempre sob sistema tradicional de manejo do solo.

O tipo climático da região é o Cwa, de acordo com a classificação de Köppen, tropical úmido com inverno seco, temperatura média do mês mais frio inferior a $18^{\circ} \mathrm{C}$ e a do mês mais quente não ultrapassando $22^{\circ} \mathrm{C}$; o total das chuvas do mês mais seco não ultrapassa 30 mm e o índice pluviométrico varia entre 1.100 e $1.700 \mathrm{~mm}$ $\mathrm{ano}^{-1}$. A vegetação natural da região aparece isoladamente como maciços residuais de floresta latifoliada tropical, o solo foi classificado como Latossolo Vermelho e as litologias são representadas por materiais de alterações de rochas do Grupo Bauru, sobrepondo rochas básicas (basalto) (IPT, 1981).

\section{Análises e determinações}

As descrições morfológicas (LEMOS \& SANTOS, 1996) conduziram a escolha dos pontos de amostragem nos perfis de solos, entre plantas, nas seguintes profundidades: $0,10-0,20 \mathrm{~m}$ (amostras em local de contínua mobilização do material); 0,20$0,30 \mathrm{~m}$ (amostras subsuperficiais, que refletem os efeitos residuais do manejo agrícola); 0,60-0,70m (amostras profundas, pouco afetadas).

As amostras indeformadas foram submetidas à análise granulométrica seguindo recomendações da EMBRAPA (1979). Também foram coletadas amostras em anéis volumétricos de $100 \mathrm{~cm}^{3}$, para determinação da porosidade e da densidade do solo. Alguns pontos foram amostrados individualmente, para análises micromorfológicas, particularmente onde se observam certos comprometimentos da estrutura, possibilitando comparações com camadas mais profundas e menos influenciadas pelo manejo. Nestes casos, amostras indeformadas foram coletadas em caixas de Kubiena, impregnadas com uma mistura de Resina Ortoftálica T208, Monômero de Estireno (diluente) e Butanox (catalisador), e em seguida dessecadas e seccionadas em lâminas delgadas para observações em microscópio petrográfico (BULLOCK et al., 1985). Testes de infiltração de água foram realizados com permeâmetro de carga constante, modelo modificado a partir do Permeâmetro de Guelph, desenvolvido por REYNOLDS \& ELRICK, (1985). As leituras foram feitas com cargas hidráulicas de $0,6 \mathrm{kPa}$, repetindo-se até as leituras atingirem taxa constante.

O plano amostral utilizado para análise estatística consistiu de dez coletas simples casualizadas, nas referidas profundidades, com distância mínima de $25 \mathrm{~m}$, que foram avaliadas estatisticamente pelo confronto de médias, duas a duas, pelo teste t de Student a $5 \%$ de probabilidade de erro.

\section{RESULTADOS E DISCUSSÃO}

Morfologia e granulometria

Os solos cultivados com citros e cana-deaçúcar evidenciaram diferenças em suas estruturas, tanto nas camadas superficiais quanto em subsuperfície. Em se tratando de mesma unidade do solo e mesma posição na paisagem, estas modificações

Ciência Rural, v.35, n.2, mar-abr, 2005. 
só podem ser atribuídas a modificações decorrentes das práticas utilizadas nas duas culturas.

A estrutura em subsuperfície é predominantemente poliédrica, com blocos fortemente compactados, grandes e médios, de consistência dura, friável, plástica e pegajosa, sem cerosidade evidente, com exceção dos horizontes B1 e B2 da área de citros, onde se observou cerosidade fraca e descontínua, sobrepondo-se ao Bw, nitidamente latossólico (Tabela 1). Esse aumento vertical do teor de argila, de $210 \mathrm{~g}$ $\mathrm{kg}^{-1}$ para $310 \mathrm{~g} \mathrm{~kg}^{-1}$ no citros (Tabela 2) deve decorrer de processos de translocação, que operam também ao longo da vertente, a partir da posição a montante (SOARES \& ESPINDOLA, 2001).

A cor do solo apresenta-se brunoavermelhado-escura nas camadas superiores e vermelho-escuro em profundidade, mostrando influência dos óxidos de ferro oriundos de alterações basálticas na composição desses solos, o que é mais evidente em posições de sopé. Foi observado um volume sinuoso nos contatos entre os horizontes superficiais, em decorrência das práticas mecânicas de manejo, mostrando zonas virtualmente compactadas ao lado de bolsões sem compactação, com estrutura composta de blocos pequenos juntamente com grânulos e consistência solta. Esta situação, comum nas áreas de citros, ocorre em decorrência da regularidade do tráfego nas culturas perenes, originando setores compactados e não compactados. Notam-se poros grandes e galerias em todo o perfil, por ação da mesofauna do solo, mesmo em áreas compactadas, que favorecem a penetração de raízes. A consistência dos horizontes BA, tanto no citros como na cana-de-açúcar, é bastante tenaz quando o solo está seco, mantendo-se firme quando úmido. Isso é indicativo de processos de compactação mecânica, principalmente à profundidade de 0,20 a 0,30m da superfície.

As análises granulométricas revelam mudança abrupta nos teores de argila de A para B, variando de $210 \mathrm{~g} \mathrm{~kg}^{-1}$ para $310 \mathrm{~g} \mathrm{~kg}^{-1}$ no citros e de $260 \mathrm{~g} \mathrm{~kg}^{-1}$ para $330 \mathrm{~g} \mathrm{~kg}^{-1}$ na cana-de-açúcar (Tabela 2).

Tabela 1 - Características morfológicas dos solos.

\begin{tabular}{|c|c|c|c|c|c|c|c|c|}
\hline \multirow{2}{*}{\multicolumn{2}{|c|}{ Horizonte (m) }} & \multirow{2}{*}{ Cor } & \multirow{2}{*}{ Textura* } & \multirow{2}{*}{ Estrutura } & \multicolumn{3}{|c|}{ Consistência } & \multirow{2}{*}{ Transição } \\
\hline & & & & & Seco & Úmido & Molhado & \\
\hline \multicolumn{9}{|c|}{ Citros } \\
\hline Ap & $0-0,07$ & $\begin{array}{l}\text { Bruno- } \\
\text { avermelhado } \\
\text { escuro, 2,5YR 3/4 }\end{array}$ & Média & $\begin{array}{l}\text { Granular pequena } \\
\text { moderada fraca e grãos } \\
\text { simples }\end{array}$ & Solta & Solta & $\begin{array}{l}\text { Plástica e } \\
\text { pegajosa }\end{array}$ & $\begin{array}{l}\text { Plana e } \\
\text { abrupta }\end{array}$ \\
\hline BA & $0,07-, 40$ & $\begin{array}{l}\text { Vermelho } \\
\text { escuro, } 2,5 \text { YR } 3 / 6\end{array}$ & Média & Blocos grandes fortes & Muito dura & Firme & $\begin{array}{l}\text { Plástica e } \\
\text { pegajosa }\end{array}$ & Plana e clara \\
\hline B1 & $0,40-0,60$ & $\begin{array}{l}\text { Vermelho } \\
\text { escuro,2,5YR } 3 / 6\end{array}$ & Média & $\begin{array}{l}\text { Blocos subangulares que se } \\
\text { rompem, cerosidade fraca }\end{array}$ & $\begin{array}{l}\text { Ligeiramente. } \\
\text { dura }\end{array}$ & $\begin{array}{l}\text { Muito } \\
\text { friável }\end{array}$ & $\begin{array}{l}\text { Plástica e } \\
\text { pegajosa }\end{array}$ & $\begin{array}{l}\text { Suave e } \\
\text { gradual }\end{array}$ \\
\hline B2 & $0,60-1,00$ & $\begin{array}{l}\text { Bruno- } \\
\text { avermelhado } \\
\text { escuro,2,5YR 3/4 }\end{array}$ & Média & $\begin{array}{l}\text { Blocos subangulares } \\
\text { médios que se rompem }\end{array}$ & $\begin{array}{l}\text { Ligeiramete } \\
\text { dura }\end{array}$ & $\begin{array}{l}\text { Muito } \\
\text { friável }\end{array}$ & $\begin{array}{l}\text { Plástica e } \\
\text { pegajosa }\end{array}$ & $\begin{array}{l}\text { Plana e } \\
\text { gradual }\end{array}$ \\
\hline $\mathrm{Bw}$ & $1,00-0,20$ & $\begin{array}{l}\text { Vermelho } \\
\text { escuro,2,5YR3/6 }\end{array}$ & Média & $\begin{array}{l}\text { Microagregada ou granular } \\
\text { muito pequena fraca }\end{array}$ & Macia & $\begin{array}{l}\text { Muito } \\
\text { friável }\end{array}$ & $\begin{array}{l}\text { Plástica e } \\
\text { pegajosa }\end{array}$ & \\
\hline \multicolumn{9}{|c|}{ Cana-de-açúcar } \\
\hline Ap1 & $0-0,08$ & $\begin{array}{l}\text { Bruno- } \\
\text { avermelhado } \\
\text { escuro,2,5YR 3/4 }\end{array}$ & Média & $\begin{array}{l}\text { Blocos médios moderados } \\
\text { e granulares médio a } \\
\text { pequena moderada e grãos } \\
\text { simples }\end{array}$ & Dura & Friável & $\begin{array}{l}\text { Plástica e } \\
\text { pegajosa }\end{array}$ & $\begin{array}{l}\text { Suave e } \\
\text { gradual }\end{array}$ \\
\hline Ap2 & $0,08-0,38$ & $\begin{array}{l}\text { Bruno- } \\
\text { avermelhado } \\
\text { escuro,2,5YR 3/4 }\end{array}$ & Média & $\begin{array}{l}\text { Blocos fortemente } \\
\text { compactados, grandes e } \\
\text { médios cerosidade fraca }\end{array}$ & $\begin{array}{l}\text { Extremamente } \\
\text { dura }\end{array}$ & Firme & $\begin{array}{l}\text { Plástica e } \\
\text { pegajosa }\end{array}$ & $\begin{array}{l}\text { Suave e } \\
\text { gradual }\end{array}$ \\
\hline Bw1 & $0,38-0,70$ & $\begin{array}{l}\text { Vermelho } \\
\text { escuro,2,5YR 3/6 }\end{array}$ & Argilosa & $\begin{array}{l}\text { Blocos médios moderados } \\
\text { que se rompem }\end{array}$ & Dura & Friável & $\begin{array}{l}\text { Plástica e } \\
\text { pegajosa }\end{array}$ & $\begin{array}{l}\text { Suave e } \\
\text { gradual }\end{array}$ \\
\hline Bw2 & $0,70-0,30$ & $\begin{array}{l}\text { Bruno- } \\
\text { avermelhado } \\
\text { escuro,2,5YR 3/4 }\end{array}$ & Argilosa & $\begin{array}{l}\text { Microgranular pequena } \\
\text { moderada }\end{array}$ & Macia & $\begin{array}{l}\text { Muito } \\
\text { friável }\end{array}$ & $\begin{array}{l}\text { Plástica e } \\
\text { pegajosa }\end{array}$ & \\
\hline
\end{tabular}

* Textura determinada em campo pelo método do tato. 
Tabela 2 - Características granulométricas do solo.

\begin{tabular}{|c|c|c|c|c|c|c|c|c|}
\hline & \multirow{2}{*}{ Horizonte (m) } & \multicolumn{4}{|c|}{ Granulometria } & \multirow{2}{*}{ Classe textural } & \multirow{2}{*}{ Argila natural } & \multirow{2}{*}{$\begin{array}{l}\text { Grau de } \\
\text { floculação }\end{array}$} \\
\hline & & Areia grossa & Areia fina & Silte & Argila & & & \\
\hline \multicolumn{9}{|c|}{ Citros } \\
\hline & & 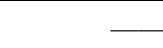 & $\mathrm{g}$ & 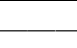 & & & $\mathrm{g} \mathrm{kg}^{-1}$ & $\%$ \\
\hline Ap & $0-0,07$ & 280 & 430 & 80 & 210 & Franco argilo- arenosa & 180 & 14 \\
\hline $\mathrm{BA}$ & $0,07-0,40$ & 260 & 460 & 70 & 210 & Franco argilo- arenosa & 200 & 4 \\
\hline B1 & $0,40-0,60$ & 240 & 380 & 70 & 310 & Franco argilo- arenosa & 270 & 13 \\
\hline B2 & $0,60-1,00$ & 220 & 390 & 70 & 320 & Franco argilo- arenosa & 290 & 9 \\
\hline BW & $1,00-1,30$ & 220 & 400 & 80 & 300 & Franco-argilo - arenosa & 300 & 0 \\
\hline \multicolumn{9}{|c|}{ Cana-de-açúcar } \\
\hline Ap1 & $0-0,08$ & 290 & 380 & 70 & 260 & Franco argilo- arenosa & 260 & 0 \\
\hline Ap2 & $0,08-0,38$ & 270 & 400 & 70 & 260 & Franco argilo- arenosa & 260 & 0 \\
\hline Bw1 & $0,38-0,70$ & 230 & 350 & 90 & 330 & Franco argilo- arenosa & 50 & 84 \\
\hline Bw2 & $0,70-1,30$ & 260 & 340 & 70 & 330 & Franco argilo- arenosa & 0 & 100 \\
\hline
\end{tabular}

Deve se observar a relativa expressão dos valores de argila dispersa em água, fator esse que deve ter contribuído sobremaneira para o elevado gradiente textural, que faz pressupor uma diminuição da taxa de infiltração de água. Além disso, essa argila pode translocar-se lateralmente, ao longo da vertente, acumulando-se principalmente nas partes mais baixas do relevo, favorecendo um acúmulo residual de grãos de quartzo nas camadas superficiais, de classes texturais mais arenosas (SOARES et al., 2002).

As observações de campo revelam uma porosidade extremamente reduzida nas camadas compactadas, porém bastante intensa nos horizontes subjacentes, sendo que, na cana-de-açúcar, há uma presença expressiva de galerias e macroporos em Bw1 e Bw2. Raízes finas e médias ocorrem ao longo dos perfis, mesmo nas camadas compactadas, com raízes grossas tendendo a um desenvolvimento horizontal, bem como ao longo dos planos de fraqueza e rachaduras entre os blocos, assim como observado por LIMA (1995). A mobilização do solo e o tráfego de máquinas e implementos agrícolas modificaram o tamanho dos agregados, e a relação macroporos e microporos, com aumento na proporção de poros pequenos em relação aos grandes. Desta forma, procederam-se comparações da macroporosida entre as culturas, uma vez que os poros grandes são altamente afetados pelo manejo dos solos (SILVA \& MIELNICZUK, 1998).

Foram verificadas diferenças no volume de macroporos entre as culturas estudadas, nas profundidades de 0,20 a 0,30 e 0,60 a $0,70 \mathrm{~m}$, com valores mais elevados no solo com citros (Tabela 3 ). Este fato pode estar relacionado ao manejo do solo mais intenso na cana-de-açúcar, que alterou a estrutura e reduziu para $0,1 \mathrm{~m}^{3} \mathrm{~m}^{-3}$ os poros de maior diâmetro, que, para VOMOCIL \& FLOCKER (1966), corresponde ao limite crítico necessário para manter condições satisfatórias de trocas gasosas e drenagem. Nos solos cultivados com citros, o sistema radicular, ao atingir camadas mais profundas, favorece o surgimento e a distribuição, no corpo do solo, dos poros de maior diâmetro (LUCARELLI, 1997).

Não se constatou diferença na densidade do solo entre as culturas estudadas na profundidade de 0 a $0,10 \mathrm{~m}$. Nas camada de 0,20 a $0,30 \mathrm{~m}$ e de 0,60 a $0,70 \mathrm{~m}$ houve diferença na densidade do solo, entre as culturas, com maiores valores em áreas com canade-açúcar, o que deve estar relacionado à maior exigência da cultura em tratos culturais, com reflexos em subsuperfície, que levaram a uma maior compactação do solo a esta profundidade, agravada pela diminuição da quantidade de matéria orgânica (SARVASI, 1994). Essas modificações estão em conformidade com os valores de densidade, devendose observar que os efeitos podem ser notados até maiores profundidades, em solos com cana-de-açúcar (CARON et al. 1996).

Observações micromorfológicas

As observações microscópicas das lâminas delgadas revelam diferenciações da geometria do espaço poroso, em conseqüência de alterações causadas pelo manejo, afetando negativamente a condição do solo de forma mais intensiva na cana-deaçúcar, mais exigente que o citros em tratos culturais (Tabela 4). A presença de estruturas associadas,

Ciência Rural, v.35, n.2, mar-abr, 2005. 
Tabela 3 - Macroporosidade, densidade do solo e teor de matéria orgânica do solo cultivado com citros e cana-de-açúcar (médias de 10 observações).

\begin{tabular}{|c|c|c|c|c|}
\hline Uso & Profundidade & Macroporosidade & Densidade do solo & Matéria orgânica \\
\hline & $\mathrm{m}$ & $\mathrm{m}^{3} \mathrm{~m}^{-3}$ & $\mathrm{Mg} \mathrm{m}^{-3}$ & $\mathrm{~g} \mathrm{~kg}^{-3}$ \\
\hline Citros & \multirow{2}{*}{$0-0,10$} & $0,172 \mathrm{a}$ & $1,287 \mathrm{a}$ & $11,7 \mathrm{a}$ \\
\hline Cana-de-açúcar & & $0,169 \mathrm{a}$ & $1,299 \mathrm{a}$ & $10,2 \mathrm{a}$ \\
\hline Citros & \multirow{2}{*}{$0,20-0,30$} & $0,137 \mathrm{a}$ & $1,373 b$ & $7,6 \mathrm{a}$ \\
\hline Cana-de-açúcar & & $0,100 b$ & $1,485 \mathrm{a}$ & $8,5 \mathrm{a}$ \\
\hline Citros & \multirow{2}{*}{$0,60-0,70$} & $0,254 a$ & $1,220 \mathrm{~b}$ & $7,6 \mathrm{a}$ \\
\hline Cana-de-açúcar & & $0,141 b$ & $1,504 \mathrm{a}$ & $4,8 \mathrm{~b}$ \\
\hline
\end{tabular}

Obs: Médias seguidas por letras iguais na mesma coluna não são significativamente diferentes a $5 \%$ pelo teste $t$

constituídas por materiais ferruginosos, deve-se à presença marcante de óxidos de ferro comum em solos com origem em rochas básicas (basalto), o que favorece a formação de agregados estáveis em água e pseudo-partículas texturais (ESPINDOLA \& GALHEGO, 1981).

No plano da lâmina, observam-se películas de argila envolvendo grãos de quartzo e preenchendo espaços vazios, apresentando-se como pontes de argila iluvial ligando grãos de quartzo e microagregados. Esta constatação tem suporte em análises de laboratório, que apontam teores elevados de argila natural e relevo favorável a um deslocamento vertical e oblíquo-lateral das partículas finas.

As lâminas delgadas ilustram a redução da porosidade nos horizontes subsuperficiais dos solos, por alteração das cavidades porais, determinada pelo uso agrícola intensivo conforme já havia sido observado nas descrições morfológicas. Nos solos cultivados com citros, em subsuperfície, há modificação da contextura matricial por achatamento de agregados e o preenchimento dos espaços porosos, fazendo surgir formas fissuradas, e estrutura em blocos, em ambiente originalmente microagregado como mostra a figura 1. Nas camadas mais profundas, os constituintes do solo apresentam formas naturais, com a porosidade mamelonar comunicante e estrutura microagregada (Figura 1). O sistema radicular fasciculado da cana-de-açúcar favorece o surgimento de macroporos irregulares, ao mesmo tempo em que o manejo intensivo faz surgir poros planares, indicativos de horizontes compactados em subsuperfície (Figura 1). Nas camadas mais profundas, a exemplo do que ocorre nos solos com citros, o ambiente permite a ocorrência de macroporos comunicantes e estrutura microagregada, observado na figura 1 .

As análises micromorfológicas, além de ratificarem as observações de campo, permitem constatar que a redução da macroporosidade é mais intensa nos solos cultivados com cana-de-açúcar, mais exigente em tratos culturais, com diâmetro de poros inferior a $90 \mu \mathrm{m}$. Embora limitando o livre desenvolvimento das raízes, esta condição não impede a expansão radicular, assim como a atividade macrobiológica, pois grande parte dos

Tabela 4 - Características micromorfológicas do solo.

\begin{tabular}{|c|c|c|c|c|}
\hline Profundidade(m) & Contextura matricial & Microestrutura e pedalidade & Porosidade & Estruturas associadas \\
\hline \multicolumn{5}{|c|}{ Citros } \\
\hline $0,20-0,30$ & $\begin{array}{l}\text { Fundo matricial enáulico } \\
\text { com setores gefúricos }\end{array}$ & $\begin{array}{c}\text { Agregados subarredondados em } \\
\text { forma de blocos e pedalidade } \\
\text { moderada }\end{array}$ & $\begin{array}{l}\text { Poros mamelonados e } \\
\text { fissuras }\end{array}$ & $\begin{array}{l}\text { Achatamento de } \\
\text { microagregados } \\
\text { formando blocos }\end{array}$ \\
\hline $0,60-0,70$ & Fundo matricial enáulico & $\begin{array}{l}\text { Estrutura microagregada com } \\
\text { pedalidade forte }\end{array}$ & $\begin{array}{l}\text { Poros mamelonados } \\
\text { comunicantes }\end{array}$ & Argila iluvial \\
\hline \multicolumn{5}{|c|}{ Cana-de-açúcar } \\
\hline $0,20-0,30$ & Fundo matricial porfírico & $\begin{array}{l}\text { Blocos subangulares e } \\
\text { pedalidade fraca }\end{array}$ & $\begin{array}{l}\text { Poros de empilhamento e } \\
\text { microfissuras }\end{array}$ & $\begin{array}{l}\text { Material orgânico e } \\
\text { ferruginoso }\end{array}$ \\
\hline $0,60-0,70$ & $\begin{array}{l}\text { Fundo matricial enáulico } \\
\text { com setores porfíricos }\end{array}$ & $\begin{array}{l}\text { Microagregada arredondade } \\
\text { com pedalidade forte }\end{array}$ & $\begin{array}{l}\text { Macroporos } \\
\text { interagregados }\end{array}$ & Argila iluvial \\
\hline
\end{tabular}

Ciência Rural, v.35, n.2, mar-abr, 2005. 


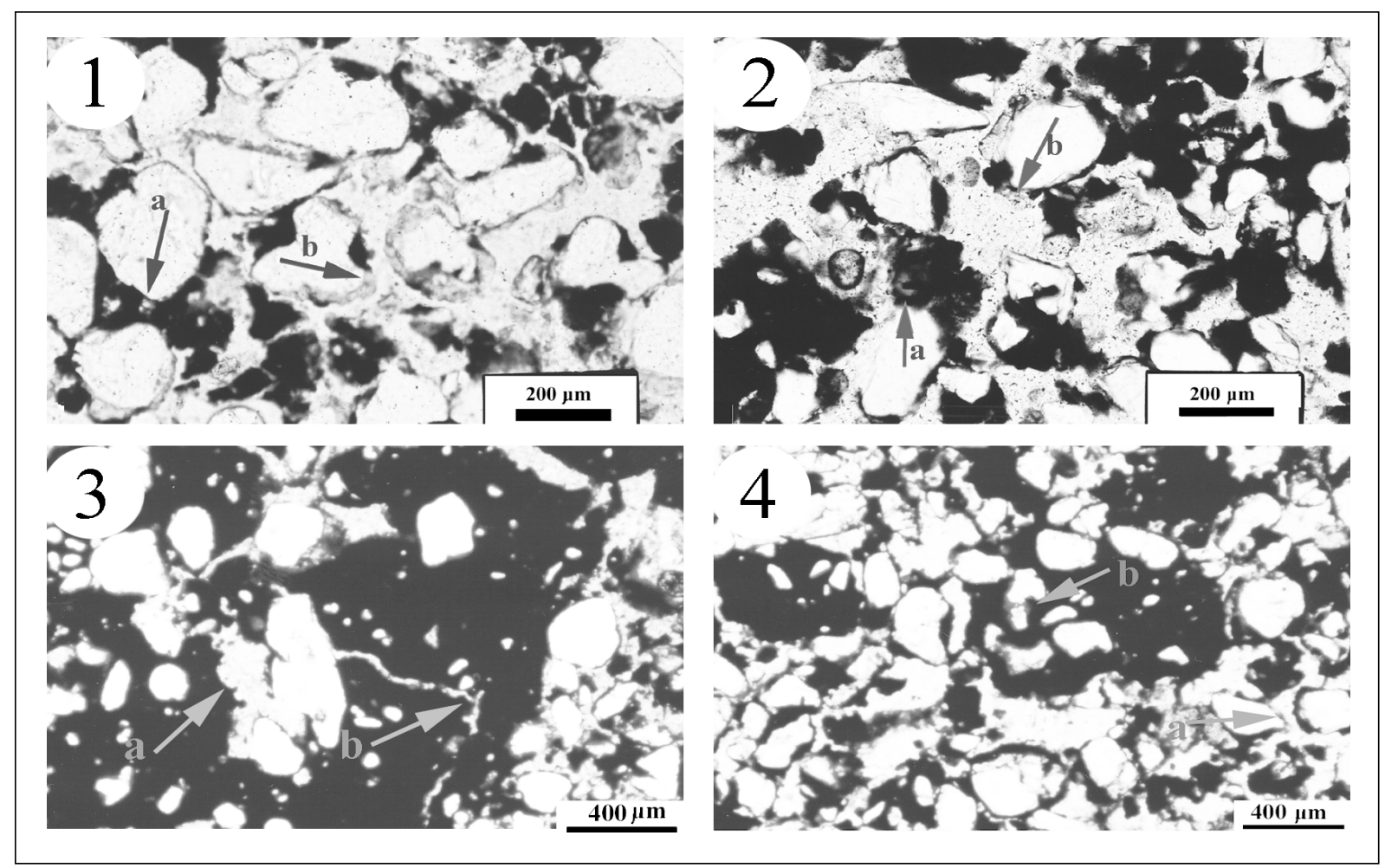

Figura 1 - (1) Fotomicrografia do solo cultivado com citros na profundidade de 0,20-0,30m: a) achatamento de agregado e b) poro com geometria modificada. (1.2) Fotomicrografia do solo cultivado com citros na profundidade de 0,60 a $0,70 \mathrm{~m}$ : a) macroporo mamelonado comunicante e b) argila iluvial e estrutura microagregada. (1.3) Fotomicrografia do solo cultivado com cana-de-açúcar na profundidade de 0,20 a 0,30m: a) macroporo não comunicante e b) microfissuras planas e oblíquas. (1.4) Fotomicrografia do solo cultivado com cana-de-açúcar na profundidade de 0,60 a $0,70 \mathrm{~m}:$ a) grão de quartzo e poros comunicantes arredondado e b) filme de argila ligando microagregado.

poros não chegou a atingir a condição de microporos, como atestam as ocorrências de excrementos (de atividade biológica) e de macroporos isolados, que facilitam a dinâmica da água e do ar.

Infiltração da água no solo

A capacidade do solo em permitir a infiltração da água e as trocas gasosas entre a atmosfera e a rizosfera é reflexo do seu volume de macroporos (THOMASSON, 1978), visto que o seu comportamento hidrodinâmico reflete as suas condições físicas. Esta assertiva se confirma nos solos estudados, que revelam alterações nas taxas de infiltração de água, decorrentes do uso e manejo agrícola praticados.

Nos solos cultivados com cana-de-açúcar, na camada de 0,20-0,30m, observou-se forte redução da taxa de infiltração da água, quando comparada com o solo com citros. Este fato pode ser atribuído à redução da macroporosidade, em consequiência das práticas culturais mais intensas na cana-de-açúcar, com médias inferiores às do citros ao longo dos perfis, sendo mais evidente em subsuperfície. Os valores na camada de 0 a $0,10 \mathrm{~m}$ apresentaram-se com $21,25 \mathrm{~mm} \mathrm{~min}^{-1}$ no citros, alterando-se para $3,5 \mathrm{~mm} \mathrm{~min}^{-1}$ na cana-de-açúcar. Em subsuperfície, a diferença é de $16 \mathrm{~mm} \mathrm{~min}^{-1}$ para $4,25 \mathrm{~mm} \mathrm{~min}^{-1}$, o que reforça o comprometimento da estrutura do solo com práticas tradicionais de manejo (LUCARELLI, 1997). Outro aspecto é a diminuição dos teores de matéria orgânica, com desestruturação do solo e compactação, além do possível preenchimento de espaços vazios por argila dispersa em água. Nos solos cultivados com citros, o menor revolvimento do solo favorece a atividade biológica e o surgimento de macroporos comunicantes, que facilitam a movimentação da água.

Avaliando-se separadamente os solos cultivados na profundidade de 0,60 a $0,70 \mathrm{~m}$, observam-se valores médios de infiltração da água mais elevados no solo com citros, o que deve estar relacionado a uma posição praticamente não atingida pelo manejo (DALLA ROSA, 1981) e ao sistema

Ciência Rural, v.35, n.2, mar-abr, 2005. 
radicular profundo da cultura, favorecendo o movimento da água nas camadas inferiores dos perfis. Na cana-de-açúcar, a desestruturação excessiva do solo pode promover uma grande quantidade de partículas finas em suspensão, as quais seriam responsáveis pela obstrução parcial dos poros.

\section{CONCLUSÕES}

Os parâmetros analisados mostram que os diferentes manejos praticados na cana-de-açúcar e no citros promovem impactos negativos em graus distintos de ocorrência: mais intensos na cana-deaçúcar, onde as práticas são mais intensivas e impactantes.

A compactação mecânica foi evidenciada nos diversos parâmetros analisados, refletindo os efeitos negativos da destruição da estrutura: elevação da densidade do solo, diminuição da macroporosidade e da taxa de infiltração no perfil.

Apesar das modificações negativas ocorridas nos atributos dos solos, após o longo período submetido a formas tradicionais de uso e manejo, observa-se que elas não impedem a contínua exploração do recurso natural solo; porém, é certo que o emprego de práticas menos intensivas, que mobilizam pouco o solo, concorreria para melhores resultados, em função da maior acumulação de matéria orgânica e menor degradação da estrutura, com vantagens econômicas e ambientais.

\section{REFERÊNCIAS BIBLIOGRÁFICAS}

BULLOCK, P. et al. Handbook for soil thin section description. England : Waine Research, 1985. 152p.

CARON, J. et al. Soil structural stability during rapid wetting: influence of land use on some aggregate properties. Soil Science Society of America Journal, v.60, p.901-908, 1996

CARPENEDO, V.; MIELNICZUK, J. Estado de agregação e qualidade de agregados de Latossolos Roxos submetidos a diferentes sistemas de manejo. Revista Brasileira de Ciencia do Solo, v.14, p.99-105, 1990

DALLA ROSA, A. Práticas mecânicas e culturais na recuperação de características físicas de solos degradados pelo cultivo do solo em Santo Ângelo (Latossolo Roxo Distrófico). 1981. 136f. Dissertação (Mestrado em Ciência do Solo) - Universidade Federal do Rio Grande do Sul.

DREES, L.R. et al. Micromorpological characteristics of longterm no-till and conventional tilled soils. Soil Science Society of America Journal, v.58, p.508-517, 1994.
EMBRAPA (SNLCS). Serviço Nacional de Levantamento e Conservação de Solos. Manual de métodos e análise de solo. Rio de Janeiro : EMBRAPA Solos, 1979. np

ESPINDOLA, C.R.; GALHEGO, H.R. Pseudo-partículas texturais em solos basálticos da região Central de São Paulo. In: CONGRESSO BRASILEIRO DE CIÊNCIA DO SOLO, 18., 1981, Salvador, BA. Resumos... Salvador : Sociedade Brasileira de Ciência do Solo, 1981. p.22-23.

IPT - Instituto de Pesquisas Tecnológicas do Estado de São Paulo: Mapa Geológico do Estado de São Paulo. São Paulo, 1981.

LEMOS, R.C.; SANTOS, R.D. Manual de descrição e coleta de solos no campo. 3.ed. Campinas : Sociedade Brasileira de Ciência do Solo, 1996. 84p.

LIMA, J.M.J.C.L. Alterações das propriedades dos solos cultivados com cana-de-açúcar. 1995. 164f. Tese (Doutorado em Física do Solo) - Escola Superior de Agricultura "Luiz de Queiroz", Universidade de São Paulo.

LUCARELLI, J.R.F. Alterações em características de um Latossolos Roxo submetido a diferentes sistemas de manejo. 1997. 87f. Dissetação (Mestrado em Engenharia Agrícola) Faculdade de Engenharia Agrícola.

REYNOLDS, W.D.; ELRICK, D.E. I n situ measurement of fieldsatured hydraulic conductivity, sorptivity and the $\alpha$-permeameters using the Guelph permeameter. Journal of Soil Science, v.140, p.292-302, 1985

RUELLAN, A. Contribuição das pesquisas em zona tropical ao desenvolvimento da Ciência do Solo. In: CONGRESSO BRASILEIRO DE CIÊNCIA DO SOLO, 21., 1987, Campinas, SP. Anais... Campinas : SBCS, 1988. p.405-414.

SARVASI, F.O.C. Dinâmica da água, erosão hídrica e produtividade das culturas em função do preparo do solo. 1994. 147f. Dissertação (Mestrado em Engenharia Agrícola) - Escola Superior de Agricultura "Luiz de Queiroz", Universidade de São Paulo.

SILVA, I.F.; MIELNICZUK, J. Sistemas de cultivo e características do solo afetando a estabilidade de agregados. Revista Brasileira de Ciência do Solo, v.22, p.311-317, 1998.

SOARES, J.L.N.; ESPINDOLA, C.R. Atributos físicos de um argissolo sob mata nativa em Bariri, SP. In: CONGRESSO BRASILEIRO DE CIÊNCIA DO SOLO, 28., 2001, Londrina, PR. Resumos... Londrina : Sociedade Brasileira de Ciência do Solo, 2001. p.18.

SOARES, J.L.N. et al. Variação de parâmetros pedológicos ao longo de uma seqüência topográfica com citros, em Bariri, SP. Revista Brasileira de Ciência do solo, (Submetido para publicação) 2002.

TAVARES FILHO, J. et al. Método do perfil cultural para avaliação do estado físico de solos em condições tropicais. Revista Brasileira de Ciência do Solo, v.23, p.393-399, 1999.

THOMASSON, A.J. Towards an objective classification of soil structure. Journal of Soil Science, v.29, p.38-46, 1978.

VOMOCIL, J.A.; FLOCKER, W.J. Effects of soil compaction on storage and movement of soil, air and water. American Society Agricultural Engineering, v.4, p.242-246, 1966.

Ciência Rural, v.35, n.2, mar-abr, 2005. 